\title{
Effects of tobacco smoke and electronic cigarette vapor exposure on the oral and gut microbiota in humans: a pilot study
}

\author{
Christopher J Stewart ${ }^{\text {Corresp., }}{ }^{1,2}$ ， Thomas A Auchtung ${ }^{1}$ ， Nadim J Ajami ${ }^{1}$ ， Kenia Velasquez ${ }^{3,4}$ ， Daniel P Smith ${ }^{1}$, \\ Richard De La Garza, II ${ }^{3,4,5}$, Ramiro Salas ${ }^{3,4,5}$, Joseph F Petrosino ${ }^{1}$ \\ ${ }^{1}$ Alkek Center for Metagenomics and Microbiome Research, Department of Molecular Virology and Microbiology, Baylor College of Medicine, Houston, \\ Texas, United States \\ 2 Institute for Cellular Medicine, Newcastle University, Newcastle, United Kingdom \\ 3 Menninger Department of Psychiatry and Behavioral Sciences, Baylor College of Medicine, Houston, Texas, United States \\ 4 Veteran Affairs Medical Center, Michael E DeBakey VA Medical Center, Houston, Texas, United States \\ 5 Department of Neuroscience, Baylor College of Medicine, Houston, United States \\ Corresponding Author: Christopher J Stewart \\ Email address: christopher.stewart@bcm.edu
}

Background: The use of electronic cigarettes has increased drastically over the past five years, primarily as an alternative to smoking tobacco cigarettes. However, the adverse effects of acute and long-term use of electronic cigarettes on the microbiota have not been explored. In this pilot study, we sought to determine if electronic cigarettes or tobacco smoking alter the oral and gut microbiota in comparison to non-smoking controls.

Methods: We examined a human cohort consisting of 30 individuals: 10 electronic cigarette users, 10 tobacco smokers, and 10 controls. We collected cross-sectional fecal, buccal swabs, and saliva samples from each participant. All samples underwent V4 16S rRNA gene sequencing.

Results: The fecal and buccal microbiota profiles were significantly different in tobacco smokers compared to electronic cigarette users and controls, with an increased relative abundance of Prevotella and decreased Bacteroides. Compared to controls, Shannon diversity was significantly reduced $(P=$ $0.009)$ in fecal samples collected from tobacco smokers, but richness was significantly increased $(P=$ 0.003 ) in buccal swabs from tobacco smokers. No significant difference was found in the alpha diversity, beta-diversity or taxonomic relative abundances between electronic cigarette users and controls.

Discussion: From a microbial ecology perspective, the current pilot data demonstrate that the use of electronic cigarettes may represent a safer alternative compared to tobacco smoking. However, validation in larger cohorts and greater understanding of the short and long-term impact of electronic cigarette use on microbiota composition and function is warranted. 
1 Effects of tobacco smoke and electronic cigarette vapor exposure on the oral and gut 2 microbiota in humans: A pilot study

3

4 Christopher J Stewart ${ }^{1,2}$, Thomas A Auchtung ${ }^{1}$, Nadim J Ajami ${ }^{1}$, Kenia Velasquez ${ }^{3,4}$, Daniel P 5 Smith $^{1}$, Richard De La Garza, II ${ }^{3,4,5}$, Ramiro Salas ${ }^{3,4,5}$, Joseph F Petrosino ${ }^{1}$

$7{ }^{1}$ Department of Molecular Virology and Microbiology, Baylor College of Medicine, Houston, 8 Texas, USA

9 Institute for Cellular Medicine, Newcastle University, Newcastle upon Tyne, UK

$10{ }^{3}$ Menninger Department of Psychiatry and Behavioral Sciences, Baylor College of Medicine, 11 Houston, Texas, USA

$12{ }^{4}$ Veteran Affairs Medical Center, Michael E DeBakey VA Medical Center, Houston, Texas, 13 USA

$14{ }^{5}$ Department of Neuroscience, Baylor College of Medicine, Houston, Texas, USA

16 Corresponding author

17 Christopher J Stewart, Ph.D.

18 Email: christopher.stewart@newcastle.ac.uk 


\section{ABSTRACT}

23 Background: The use of electronic cigarettes has increased drastically over the past five years,

24 primarily as an alternative to smoking tobacco cigarettes. However, the adverse effects of acute

25 and long-term use of electronic cigarettes on the microbiota have not been explored. In this pilot

26 study, we sought to determine if electronic cigarettes or tobacco smoking alter the oral and gut

27 microbiota in comparison to non-smoking controls.

28 Methods: We examined a human cohort consisting of 30 individuals: 10 electronic cigarette

29 users, 10 tobacco smokers, and 10 controls. We collected cross-sectional fecal, buccal swabs,

30 and saliva samples from each participant. All samples underwent V4 16S rRNA gene

31 sequencing.

32 Results: Tobacco smoking had a significant effect on the bacterial profiles in all sample types

33 when compared to controls, and in feces and buccal swabs when compared to electronic cigarette

34 users. The most significant associations were found in the gut, with an increased relative

35 abundance of Prevotella $(P=0.006)$ and decreased Bacteroides $(P=0.036)$ in tobacco smokers.

36 The Shannon diversity was also significantly reduced $(P=0.009)$ in fecal samples collected from

37 tobacco smokers compared to controls. No significant difference was found in the alpha

38 diversity, beta-diversity or taxonomic relative abundances between electronic cigarette users and

39 controls.

40 Discussion: From a microbial ecology perspective, the current pilot data demonstrate that the use

41 of electronic cigarettes may represent a safer alternative compared to tobacco smoking.

42 However, validation in larger cohorts and greater understanding of the short and long-term

43 impact of electronic cigarette use on microbiota composition and function is warranted. 


\section{INTRODUCTION}

45

46

47

Tobacco cigarettes are the leading cause of preventable diseases in the world (Cahn \& Siegel, 2011). Smoking increases the risk for development of several diseases, including cardiovascular disease (Lubin et al., 2016), various cancers (Jacobs et al., 2015) and especially lung cancer (Montserrat-Capdevila et al., 2016), and inflammatory bowel disease (Higuchi et al., 2012). Electronic cigarettes offer promise as a tool to quit or an alternative to tobacco smoking. It is estimated that over $12 \%$ of adults in the US have used ECs (Kosmider et al., 2016). Use of ECs is tripling annually with consumers including non-tobacco smoking adolescents and adults (Moon, Lee \& Lee, 2015; Bostean, Trinidad \& McCarthy, 2015). While ECs primarily contain propylene glycol, vegetable glycerin, and nicotine, tobacco cigarettes are composed of over 4000 other chemicals and particulate matter (You et al., 2015). Studies reporting negative health effects relating to ECs are scarce and ECs remain unregulated, but commercial ECs have been reported to contain low levels of toxic compounds (Cahn \& Siegel, 2011; Varlet et al., 2015; Kosmider et al., 2016; Allen et al., 2016).

There are relatively few studies exploring the effects of tobacco smoke on the microbiota and we are not aware of any study to date that has compared the bacterial communities in tobacco smokers and electronic cigarette users. In one human study, the oral microbiota was altered between healthy non-smokers and tobacco smokers, with decreased Porphyromonas, Neisseria, and Gemella in tobacco smokers, but the lung communities were not affected (Morris et al., 2013). Smoking has also been shown to drive changes in the sputum microbiota more than other lifestyle factors (e.g., exercise and alcohol), increasing the relative abundance of Veillonella and Megasphaera (Lim et al., 2016). A recent large-scale sequencing study of the oral microbiota in current, previous, or non- smokers demonstrated current smokers had distinct 
67 oral communities, with reduced relative abundance of Proteobacteria (Wu et al., 2016). Notably,

68 the significant taxa vary between studies and a recent analysis of numerous sites within the

69 mouth found no significant difference between smokers and controls in any site, with the

70 exception of the buccal mucosa (Yu et al., 2017). Quitting smoking has been shown to increase

71 bacterial diversity and alter community composition in both the mouth (Delima et al., 2010) and

72 gut (Biedermann et al., 2013). Besides human cohort research, the gut microbiota has been

73 shown to differ in tobacco smoke exposed mice, in comparison to air-only exposure (Wang,

74 2012; Allais et al., 2016).

75 The current study represents the first exploration of the effect of electronic cigarette 76 vapor and tobacco smoke exposure on the oral (buccal and saliva) and gut bacterial communities.

\section{MATERIALS AND METHODS}

\section{Study design and cohort}

The study was approved by the Baylor College of Medicine Institutional Review Board (IRB H-38043). Written informed consent was obtained prior to collection of data and samples.

The cohort consisted of 30 individuals in 3 distinct exposure groups; electronic cigarette

users $(n=10)$, tobacco smokers $(n=10)$, and matched controls $(n=10)$. All participants were recruited from the Houston area. Inclusion criteria for electronic cigarette users included daily use of electronic cigarettes for at least 6 months. Inclusion criteria for tobacco smokers included an Fagerstrom Test for Nicotine Dependence (FTND) $\geq 4$ and smoked a minimum of 10 cigarettes per day. Subject variables between the 3 exposure groups were comparable, with no significant difference in the sex, age, diet, height/weight, or race (Table 1). Notably, only 2/30 
90 samples were from female participants. One electronic cigarette user (EC7) reported occasionally

91 smoking one tobacco cigarette per week and no other electronic cigarette users reported use of

92 tobacco cigarettes. EC7 had a comparable carbon monoxide (CO) ppm to other electronic

93 cigarette users and controls. No tobacco smokers reported use of electronic cigarettes. Electronic

94 cigarette users vaped regularly throughout the day, used electronic cigarettes daily, and had been

95 actively using electronic cigarettes for a median of 3 years.

97 DNA extraction

98 DNA was extracted from $125 \mathrm{mg}$ of fresh fecal samples using the AllPrep Bacterial kit

99 (MoBio 47054) as per the manufacturers' protocol. Entire buccal swabs and $500 \mu 1$ saliva

100 samples were extracted using the PowerMicrobiome RNA isolation kit (MoBio 26000-50) as per

101 the manufacturers' protocol, omitting the necessary steps for co-elution of DNA and RNA, and 102 with elution of nucleic acids in $50 \mu 1$.

103

\section{16S rRNA gene sequencing}

105 The bacterial 16S rRNA gene V4 region was amplified by PCR using barcoded Illumina

106 adapter-containing primers 515F and 806R (Caporaso et al., 2012) and sequenced with the 2x250

107 bp cartridges in the MiSeq platform (Illumina). The read pairs were demultiplexed and reads

108 were merged using USEARCH v7.0.1090 (Edgar, 2010). Merging allowed zero mismatches and

109 a minimum overlap of 50 bases, and merged reads were trimmed at the first base with a $\mathrm{Q} \leq 5$. A

110 quality filter was applied to the resulting merged reads and those containing above $0.5 \%$

111 expected errors were discarded. Sequences were stepwise clustered into Operational Taxonomic

112 Units (OTUs) at a similarity cutoff value of 97\% using the UPARSE algorithm (Edgar, 2013). 
113 Chimeras were removed using USEARCH v7.0.1090 and UCHIME. To determine taxonomies,

114 OTUs were mapped to a version of the SILVA Database (Quast et al., 2013) containing only the

115 16S V4 region using USEARCH v7.0.1090. Abundances were recovered by mapping the merged

116 reads to the UPARSE OTUs. A rarefied OTU table was constructed from the output files

117 generated in the previous two steps for downstream analyses of alpha-diversity, beta-diversity

118 (including UniFrac), and phylogenetic trends (Lozupone \& Knight, 2005).

119

120 Statistical Analysis

121 Samples were rarefied to 4,000 reads and rarefaction resulted in the loss of all negative

122 controls for each DNA extraction kit. Analysis and visualization of bacterial communities was

123 conducted in R (Team, 2014). For analysis of alpha diversity and taxonomic relative abundance,

124 the Kruskal-Wallis test (Kruskal \& Wallis, 1952) was first applied to determine the overall

125 statistical significance of the three groups. Only if the Kruskal-Wallis test showed a $\mathrm{P}$ value

$126<0.05$, pairwise significance was determined based on the Mann-Whitney test (Mann \& Whitney,

127 1947). Differences in beta diversity (weighted Unifrac distance) were assessed using

128 PERMANOVA. Linear regression was performed in R using the $\operatorname{lm}()$ function. When comparing

129 more then one measure, such as multiple measures of alpha-diversity or for multiple taxonomic

130 genera, P-values were adjusted for multiple comparisons with the false discovery rate (FDR)

131 algorithm (Benjamini \& Hochberg, 1995).

132 All data and metadata files, as well as the $\mathrm{R}$ code used in the analysis, are provided in the 133 supplement.

134

135 RESULTS 


\section{Microbiota specific to sample site}

138 Feces had a distinct bacterial profile compared to the oral samples (buccal swab and

139 saliva) (Figure S1A). The Shannon diversity indices showed a significant increase in saliva $(P<$

140 0.001) and feces $(P<0.001)$ in comparison to buccal swab samples (Figure S1B). Dominant

141 bacterial genera were also significantly different $(P<0.001)$ between the three sample types

142 (Figure S1C). Thus, analyses exploring the effects of tobacco smoking or electronic cigarette

143 use were stratified by sample type.

\section{Alpha diversity of feces is reduced in tobacco smokers}

146 The Shannon diversity was significantly reduced in fecal samples collected from tobacco

147 smokers compared to controls $(P=0.009)$, but the number of observed operational taxonomic

148 units (OTUs) was comparable between all groups (Figure 1A). No significant difference was

149 found in the number of OTUs or Shannon diversity between the groups in buccal swabs and

150 saliva samples (Figure 1B and 1C).

151

152 Bacterial profiles of feces and oral sites are significantly altered in tobacco smokers

153 Weighted UniFrac PCoA, a quantitative distance metric incorporating phylogenetic

154 distances between taxa, showed tobacco smokers had significantly altered fecal bacterial profiles

155 compared to controls $(P=0.027)$ and electronic cigarette users $(P=0.009)$, but controls and

156 electronic cigarette users were not significantly different $(P=0.261)$ (Figure 2A). This was

157 consistent in buccal swabs, where bacterial profiles were significantly different between tobacco

158 smokers compared to controls $(P=0.049)$ and electronic cigarette users $(P=0.033)$, but controls 
159 and electronic cigarette users were comparable $(P=0.886)$ (Figure 2B). In saliva samples, the

160 microbiota profiles of tobacco smokers and controls were significantly different $(P=0.046)$ and

161 electronic cigarette users were comparable to both tobacco smokers and controls (Figure 2C).

162

163 The relative abundance of bacterial genera was significantly associated with tobacco

164 smoking in feces only

165 Fecal samples had a total of two genera significantly different between the three groups, 166 with increased Prevotella $(P=0.006)$ and decreased Bacteroides $(P=0.036)$ in tobacco smokers

167 (Figure 3). Further pairwise comparisons of these genera showed Prevotella had significantly

168 increased relative abundance in tobacco smokers compared to controls $(\mathrm{P}=0.008)$ and electronic

169 cigarette users $(\mathrm{P}=0.003)$, but no difference between electronic cigarette users and controls $(\mathrm{P}=$

170 0.99). Whereas Bacteroides showed significantly decreased relative abundance in tobacco

171 smokers compared to controls $(\mathrm{P}=0.017)$ and electronic cigarette users $(\mathrm{P}=0.003)$, but no

172 difference between electronic cigarette users and controls $(\mathrm{P}=0.684)$. No significant difference

173 in any bacterial genera was observed between the different groups in saliva or buccal swab

174 samples (Figure S2). These findings were also supported by correlations with CO levels, which

175 are reflective of the amount an individual smokes tobacco cigarettes. Specifically, no genus was

176 significantly associated with saliva or buccal swab samples, but Bacteroides was negatively

177 correlated with $\mathrm{CO}$ level $(\mathrm{P}=0.042)$ and Prevotella was positively correlated with CO levels $(\mathrm{P}$ $178=0.011)($ Table S1 and Figure S3).

179

180

\section{DISCUSSION}


This pilot study aimed to characterize the effects of electronic cigarette vapor and

183 tobacco smoke exposure on the bacterial profiles at multiple distinct and relevant body sites in a

184 human cohort. To our knowledge this work represents the first study to concurrently explore the

185 effect of electronic cigarette vapor and tobacco smoke exposure on the microbiota. With users of

186 ECs increasing at an unprecedented rate, it is imperative to understand the potential influences

187 on host well-being, for which the oral and gut microbiota may have important consequences.

We report, for the first time, that regular use of ECs does not measurably influence oral or gut bacterial communities. However, compared to controls, tobacco smoking had a significant effect on the bacterial profiles in all samples analyzed, with the most significant associations

191 found in the gut. This is in accordance with existing data showing the gut microbiota changes

192 following smoking cessation (Biedermann et al., 2013, 2014). This is reflected in the alpha

193 diversity analyses, where the fecal microbiota of tobacco smokers had significantly reduced

194 Shannon diversity compared to controls. Previous studies have also showed the Shannon 195 diversity is reduced in tobacco smokers compared to matched non-smokers in the gut (Opstelten 196 et al., 2016), but recovers upon smoking cessation (Biedermann et al., 2013). Although smoking 197 was recently reported to reduce buccal diversity (Yu et al., 2017), we found no difference in the 198 diversity between the groups in buccal swabs. Overall, such studies provide further evidence for 199 a direct effect of tobacco smoke in restricting microbial diversity and/or providing favorable 200 conditions for specific taxa. The reduced bacterial diversity in the gut was striking, which may

201 have important consequences for health and the risk of certain diseases. While inconclusive, 202 reduced bacterial diversity has been associated with a range of conditions, including 203 inflammatory bowel disease (Ott \& Schreiber, 2006; Durbán et al., 2012; Sha et al., 2013), 
204 obesity (Turnbaugh et al., 2009), colorectal cancer (Ahn et al., 2013), and asthma (Abrahamsson 205 et al., 2014).

206 Only the fecal microbiota was found to have specific genera significantly altered by 207 exposure, with increased relative abundance of Prevotella, in accordance with existing data 208 (Benjamin et al., 2012). Conversely, smoking tobacco cigarettes significantly decreased the 209 relative abundance of Bacteroides compared to electronic cigarette users and controls. Prevotella 210 and Bacteroides are dominant members of the human gut microbiome (Arumugam et al., 2011; 211 Koren et al., 2013; Gorvitovskaia, Holmes \& Huse, 2016). Prevotella is associated with a high 212 fiber diet and living in rural conditions (De Filippo et al., 2010; Ou et al., 2013; Tyakht et al., 213 2013; Kovatcheva-Datchary et al., 2015), whereas high Bacteroides abundance in the gut is 214 generally attributed to a protein, fat, and sugar rich diet and a Western lifestyle (De Filippo et al., 215 2010; Ou et al., 2013). Prevotella and Bacteroides may have important implications for health 216 and disease, with several species of the Bacteroides genus considered beneficial or probiotic (Xu 217 \& Gordon, 2003; Backhed et al., 2005). Existing evidence suggests intestinal inflammation, such 218 as in Crohn's disease, is associated with reduced abundance of Bacteroides (Guinane \& Cotter, 219 2013). Furthermore, a reduced Bacteroides abundance has been associated with obesity in both 220 humans (Ley et al., 2006) and mice (Ley et al., 2005; Turnbaugh et al., 2006) studies, but the 221 direct role of the microbiome in obesity causality remains an area of active discussion (Sze \& 222 Schloss, 2016). Conversely, high Prevotella in the gut has been associated with human colon 223 cancer (Chen et al., 2012; Sivaprakasam et al., 2016) and susceptibility to colitis (Elinav et al., 224 2011; Chow, Tang \& Mazmanian, 2011).

225 No taxa were significantly altered in the oral (both buccal swab and saliva) microbiota. 226 These results were surprising given the immediate proximity of the oral environment, relative to 
227 the gut, in smoke/vapor exposure. Indeed, smoking tobacco cigarettes has previously been shown

228 to significantly alter the bacterial community in oral and lung samples (Charlson et al., 2010;

229 Kozlowska et al., 2013; Mason et al., 2014; Wu et al., 2016). Conversely, existing studies have

230 also reported no changes in smokers (Morris et al., 2013) and the taxa driving the separation vary

231 between studies, which may reflect the differences in cohorts or methods, such as in specific site

232 of sample collection, extraction, sequencing, and bioinformatics (Yu et al., 2017). Thus, further

233 research in large multi-location cohorts is necessary to ascertain the direct effects of smoking

234 across respiratory sites. Notably, both Prevotella and Bacteroides were highly specific to fecal

235 samples (Table S2 and Figure S3), further demonstrating the precise effects of tobacco smoke

236 exposure on taxa endogenous to the gut.

237 This study has several potential limitations. First, the cohort information was collected by

238 questionnaire and while one electronic cigarette user reported occasional use of tobacco

239 cigarettes (1 per week maximum), it is possible other participants used tobacco cigarettes and did

240 not report this. However, to control for this we tested the CO levels (reflective of smoke

241 inhalation) in all individuals and found tobacco smokers had higher CO ppm compared to

242 electronic cigarette users and controls, which would be expected (Table 1). Second, it is possible

243 that the study was underpowered to detect subtle changes in the different sample sites and within

244 some of the patient demographics. Third, only $2 / 30$ participants in the study were female and,

245 given the potential for sex-specific microbiota profiles (Haro et al., 2016), additional work is

246 needed to determine if the findings differ between males and females. Further longitudinal work

247 with frequent sampling in larger human cohorts is needed to validate the associations reported in

248 this study and determine the potential mechanism and impact on host health. Despite an absence 
249 of taxonomic change in electronic cigarette vapor exposure, determining potential changes to

250 microbial and host functioning also represents an important area for subsequent research.

251

\section{CONCLUSIONS}

253 In summary, we found that tobacco smoking significantly alters the bacterial profiles in

254 feces, buccal, and saliva samples. Compared to controls, exposure to electronic cigarettes had no

255 effect on the oral or gut communities. Changes in the gut of tobacco smokers were associated

256 with increased relative abundance of Prevotella and decreased relative abundance of

257 Bacteroides. From a microbial ecology perspective, this study supports the perception that

258 electronic cigarettes represent a safer alternative to tobacco smoking. However, other end points

259 besides the microbiota will be important to consider when determining the impact of electronic

260 cigarettes on human health and disease. At a time when electronic cigarette use continues to rise,

261 we highlight the need for greater understanding on the direct short and long-term impact of

262 exposure to vapor on the microbiome composition and function. 


\section{Acknowledgements}

264 We also wish to thank the participants involved in this work. 


\section{5}

266

267

268

269

270

271

272

273

274

275

276

277

278

279

280

281

282

283

284

285

286

287

288

289

290

291

292

293

294

295

296

297

298

299

300

301

302

303

304

305

306

307

308

309

\section{REFERENCES}

Abrahamsson TR., Jakobsson HE., Andersson a. F., Björkstén B., Engstrand L., Jenmalm MC. 2014. Low gut microbiota diversity in early infancy precedes asthma at school age. Clinical and Experimental Allergy 44:842-850. DOI: 10.1111/cea.12253.

Ahn J., Sinha R., Pei Z., Dominianni C., Wu J., Shi J., Goedert JJ., Hayes RB., Yang L. 2013. Human Gut Microbiome and Risk for Colorectal Cancer. JNCI Journal of the National Cancer Institute 105:1907-1911. DOI: 10.1093/jnci/djt300.

Allais L., Kerckhof FM., Verschuere S., Bracke KR., De Smet R., Laukens D., Van den Abbeele P., De Vos M., Boon N., Brusselle GG., Cuvelier C a., Van de Wiele T. 2016. Chronic cigarette smoke exposure induces microbial and inflammatory shifts and mucin changes in the murine gut. Environmental Microbiology 18:1352-1363. DOI: 10.1111/14622920.12934 .

Allen JG., Flanigan SS., LeBlanc M., Vallarino J., MacNaughton P., Stewart JH., Christiani DC. 2016. Flavoring chemicals in e-cigarettes: Diacetyl, 2,3-pentanedione, and acetoin in a sample of 51 products, including fruit-, candy-, and cocktail-flavored e-cigarettes. Environmental Health Perspectives 124:733-739. DOI: 10.1289/ehp.1510185.

Arumugam M., Raes J., Pelletier E., Le Paslier D., Yamada T., Mende DR., Fernandes GR., Tap J., Bruls T., Batto J-M., Bertalan M., Borruel N., Casellas F., Fernandez L., Gautier L., Hansen T., Hattori M., Hayashi T., Kleerebezem M., Kurokawa K., Leclerc M., Levenez F., Manichanh C., Nielsen HB., Nielsen T., Pons N., Poulain J., Qin J., Sicheritz-Ponten T., Tims S., Torrents D., Ugarte E., Zoetendal EG., Wang J., Guarner F., Pedersen O., de Vos WM., Brunak S., Doré J., Antolín M., Artiguenave F., Blottiere HM., Almeida M., Brechot C., Cara C., Chervaux C., Cultrone A., Delorme C., Denariaz G., Dervyn R., Foerstner KU., Friss C., van de Guchte M., Guedon E., Haimet F., Huber W., van Hylckama-Vlieg J., Jamet A., Juste C., Kaci G., Knol J., Lakhdari O., Layec S., Le Roux K., Maguin E., Mérieux A., Melo Minardi R., M'rini C., Muller J., Oozeer R., Parkhill J., Renault P., Rescigno M., Sanchez N., Sunagawa S., Torrejon A., Turner K., Vandemeulebrouck G., Varela E., Winogradsky Y., Zeller G., Weissenbach J., Ehrlich SD., Bork P. 2011. Enterotypes of the human gut microbiome. Nature 473:174-80. DOI: 10.1038/nature09944.

Backhed F., Ley RE., Sonnenburg JL., Peterson DA., Gordon JI. 2005. Host-Bacterial Mutualism in the Human Intestine. Science 307:1915-1920. DOI: 10.1126/science. 1104816 .

Benjamin JL., Hedin CRH., Koutsoumpas A., Ng SC., McCarthy NE., Prescott NJ., PessoaLopes P., Mathew CG., Sanderson J., Hart AL., Kamm MA., Knight SC., Forbes A., Stagg AJ., Lindsay JO., Whelan K. 2012. Smokers with active Crohn's disease have a clinically relevant dysbiosis of the gastrointestinal microbiota. Inflammatory Bowel Diseases 18:1092-1100. DOI: 10.1002/ibd.21864.

Benjamini Y., Hochberg Y. 1995. Controlling the False Discovery Rate: A Practical and Powerful Approach to Multiple Testing. Journal of the Royal Statistical Society. Series B (Methodological) 57:289-300. DOI: 10.2307/2346101.

Biedermann L., Brülisauer K., Zeitz J., Frei P., Scharl M., Vavricka SR., Fried M., Loessner MJ., Rogler G., Schuppler M. 2014. Smoking cessation alters intestinal microbiota: insights from quantitative investigations on human fecal samples using FISH. Inflammatory bowel diseases 20:1496-501. DOI: 10.1097/MIB.0000000000000129.

Biedermann L., Zeitz J., Mwinyi J., Sutter-Minder E., Rehman A., Ott SJ., Steurer-Stey C., Frei 
A., Frei P., Scharl M., Loessner MJ., Vavricka SR., Fried M., Schreiber S., Schuppler M., Rogler G. 2013. Smoking cessation induces profound changes in the composition of the intestinal microbiota in humans. PloS one 8:e59260. DOI: 10.1371/journal.pone.0059260.

Bostean G., Trinidad DR., McCarthy WJ. 2015. E-cigarette use among never-smoking California students. American Journal of Public Health 105:2423-2425. DOI: 10.2105/AJPH.2015.302899.

Cahn Z., Siegel M. 2011. Electronic cigarettes as a harm reduction strategy for tobacco control: a step forward or a repeat of past mistakes? Journal of public health policy 32:16-31. DOI: 10.1057/jphp.2010.41.

Caporaso JG., Lauber CL., Walters WA., Berg-Lyons D., Huntley J., Fierer N., Owens SM., Betley J., Fraser L., Bauer M., Gormley N., Gilbert JA., Smith G., Knight R. 2012. Ultrahigh-throughput microbial community analysis on the Illumina HiSeq and MiSeq platforms. The ISME journal 6:1621-4. DOI: 10.1038/ismej.2012.8.

Charlson ES., Chen J., Custers-Allen R., Bittinger K., Li H., Sinha R., Hwang J., Bushman FD., Collman RG. 2010. Disordered microbial communities in the upper respiratory tract of cigarette smokers. PloS one 5:e15216. DOI: 10.1371/journal.pone.0015216.

Chen W., Liu F., Ling Z., Tong X., Xiang C. 2012. Human intestinal lumen and mucosaassociated microbiota in patients with colorectal cancer. PloS one 7:e39743. DOI: 10.1371/journal.pone.0039743.

Chow J., Tang H., Mazmanian SK. 2011. Pathobionts of the gastrointestinal microbiota and inflammatory disease. Current opinion in immunology 23:473-80. DOI: 10.1016/j.coi.2011.07.010.

Delima SL., McBride RK., Preshaw PM., Heasman PA., Kumar PS. 2010. Response of subgingival bacteria to smoking cessation. Journal of clinical microbiology 48:2344-9. DOI: 10.1128/JCM.01821-09.

Durbán A., Abellán JJ., Jiménez-Hernández N., Salgado P., Ponce M., Ponce J., Garrigues V., Latorre A., Moya A. 2012. Structural alterations of faecal and mucosa-associated bacterial communities in irritable bowel syndrome. Environmental Microbiology Reports 4:242-247. DOI: $10.1111 / \mathrm{j} .1758-2229.2012 .00327 . x$.

Edgar RC. 2010. Search and clustering orders of magnitude faster than BLAST. Bioinformatics 26:2460-1. DOI: 10.1093/bioinformatics/btq461.

Edgar RC. 2013. UPARSE: highly accurate OTU sequences from microbial amplicon reads. Nature methods 10:996-8. DOI: 10.1038/nmeth.2604.

Elinav E., Strowig T., Kau AL., Henao-Mejia J., Thaiss CA., Booth CJ., Peaper DR., Bertin J., Eisenbarth SC., Gordon JI., Flavell RA. 2011. NLRP6 Inflammasome Regulates Colonic Microbial Ecology and Risk for Colitis. Cell 145:745-757. DOI: 10.1016/j.cell.2011.04.022.

De Filippo C., Cavalieri D., Di Paola M., Ramazzotti M., Poullet JB., Massart S., Collini S., Pieraccini G., Lionetti P. 2010. Impact of diet in shaping gut microbiota revealed by a comparative study in children from Europe and rural Africa. Proc Natl Acad Sci USA 107:14691-6. DOI: 10.1073/pnas.1005963107.

Gorvitovskaia A., Holmes SP., Huse SM. 2016. Interpreting Prevotella and Bacteroides as biomarkers of diet and lifestyle. Microbiome 4:15. DOI: 10.1186/s40168-016-0160-7.

Guinane CM., Cotter PD. 2013. Role of the gut microbiota in health and chronic gastrointestinal disease: understanding a hidden metabolic organ. Therapeutic advances in gastroenterology 6:295-308. DOI: 10.1177/1756283X13482996. 
356

357

358

359

360

361

362

363

364

365

366

367

368

369

370

371

372

373

374

375

376

377

378

379

380

381

382

383

384

385

386

387

388

389

390

391

392

393

394

395

396

397

398

399

400

401
Haro C., Rangel-Zúñiga OA., Alcalá-Díaz JF., Gómez-Delgado F., Pérez-Martínez P., DelgadoLista J., Quintana-Navarro GM., Landa BB., Navas-Cortés JA., Tena-Sempere M., Clemente JC., López-Miranda J., Pérez-Jiménez F., Camargo A. 2016. Intestinal Microbiota Is Influenced by Gender and Body Mass Index. PLOS ONE 11:e0154090. DOI: 10.1371/journal.pone.0154090.

Higuchi LM., Khalili H., Chan AT., Richter JM., Bousvaros A., Fuchs CS. 2012. A prospective study of cigarette smoking and the risk of inflammatory bowel disease in women. The American journal of gastroenterology 107:1399-406. DOI: 10.1038/ajg.2012.196.

Jacobs EJ., Newton CC., Carter BD., Feskanich D., Freedman ND., Prentice RL., Flanders WD. 2015. What proportion of cancer deaths in the contemporary United States is attributable to cigarette smoking? Annals of epidemiology 25:179-182.e1. DOI: 10.1016/j.annepidem.2014.11.008.

Koren O., Knights D., Gonzalez A., Waldron L., Segata N., Knight R., Huttenhower C., Ley RE. 2013. A Guide to Enterotypes across the Human Body: Meta-Analysis of Microbial Community Structures in Human Microbiome Datasets. PLoS Computational Biology 9:e1002863. DOI: 10.1371/journal.pcbi.1002863.

Kosmider L., Sobczak A., Prokopowicz A., Kurek J., Zaciera M., Knysak J., Smith D., Goniewicz ML. 2016. Cherry-flavoured electronic cigarettes expose users to the inhalation irritant, benzaldehyde. Thorax:thoraxjnl-2015-207895-. DOI: 10.1136/thoraxjnl-2015207895.

Kovatcheva-Datchary P., Nilsson A., Akrami R., Lee YS., De Vadder F., Arora T., Hallen A., Martens E., Björck I., Bäckhed F. 2015. Dietary Fiber-Induced Improvement in Glucose Metabolism Is Associated with Increased Abundance of Prevotella. Cell Metabolism 22:971-982. DOI: 10.1016/j.cmet.2015.10.001.

Kozlowska J., Rivett DW., Vermeer LS., Carroll MP., Bruce KD., Mason a J., Rogers GB. 2013. A relationship between Pseudomonal growth behaviour and cystic fibrosis patient lung function identified in a metabolomic investigation. Metabolomics: Official journal of the Metabolomic Society 9:1262-1273. DOI: 10.1007/s11306-013-0538-5.

Kruskal WH., Wallis WA. 1952. Use of Ranks in One-Criterion Variance Analysis. Journal of the American Statistical Association 47:583-621.

Ley R., Bäckhed F., Turnbaugh P., Lozupone C., Knight R., Gordon J. 2005. Obesity alters gut microbial ecology. Proc Natl Acad Sci US A 102:11070-5.

Ley RE., Turnbaugh PJ., Klein S., Gordon JI. 2006. Microbial ecology: Human gut microbes associated with obesity. Nature 444:1022-1023. DOI: 10.1038/4441022a.

Lim MY., Yoon HS., Rho M., Sung J., Song Y-M., Lee K., Ko G. 2016. Analysis of the association between host genetics, smoking, and sputum microbiota in healthy humans. Scientific reports 6:23745. DOI: 10.1038/srep23745.

Lozupone C., Knight R. 2005. UniFrac: a new phylogenetic method for comparing microbial communities. Applied and environmental microbiology 71:8228-35. DOI: 10.1128/AEM.71.12.8228-8235.2005.

Lubin JH., Couper D., Lutsey PL., Woodward M., Yatsuya H., Huxley RR. 2016. Risk of Cardiovascular Disease from Cumulative Cigarette Use and the Impact of Smoking Intensity. Epidemiology 27:395-404. DOI: 10.1097/EDE.0000000000000437.

Mann HB., Whitney DR. 1947. On a Test of Whether one of Two Random Variables is Stochastically Larger than the Other. The Annals of Mathematical Statistics 18:50-60.

Mason MR., Preshaw PM., Nagaraja HN., Dabdoub SM., Rahman A., Kumar PS. 2014. The 
402

403

404

405

406

407

408

409

410

411

412

413

414

415

416

417

418

419

420

421

422

423

424

425

426

427

428

429

430

431

432

433

434

435

436

437

438

439

440

441

442

443

444

445

446

447

subgingival microbiome of clinically healthy current and never smokers. The ISME Journal 9:268-272. DOI: 10.1038/ismej.2014.114.

Montserrat-Capdevila J., Godoy P., Marsal JR., Barbé F., Galván L. 2016. Risk factors for exacerbation in chronic obstructive pulmonary disease: a prospective study. The International Journal of Tuberculosis and Lung Disease 20:389-395. DOI: 10.5588/ijtld.15.0441.

Moon JH., Lee JH., Lee JY. 2015. Subgingival microbiome in smokers and non-smokers in Korean chronic periodontitis patients. Molecular Oral Microbiology 30:227-241. DOI: 10.1111/omi.12086.

Morris A., Beck JM., Schloss PD., Campbell TB., Crothers K., Curtis JL., Flores SC., Fontenot AP., Ghedin E., Huang L., Jablonski K., Kleerup E., Lynch S V., Sodergren E., Twigg H., Young VB., Bassis CM., Venkataraman A., Schmidt TM., Weinstock GM. 2013. Comparison of the respiratory microbiome in healthy nonsmokers and smokers. American journal of respiratory and critical care medicine 187:1067-75. DOI: 10.1164/rccm.20121019130C.

Opstelten JL., Plassais J., van Mil SWC., Achouri E., Pichaud M., Siersema PD., Oldenburg B., Cervino ACL. 2016. Gut Microbial Diversity Is Reduced in Smokers with Crohn's Disease. Inflammatory bowel diseases 22:2070-7. DOI: 10.1097/MIB.0000000000000875.

Ott SJ., Schreiber S. 2006. Reduced microbial diversity in inflammatory bowel diseases. Gut 55:1207.

Ou J., Carbonero F., Zoetendal EG., DeLany JP., Wang M., Newton K., Gaskins HR., O’Keefe SJ. 2013. Diet, microbiota, and microbial metabolites in colon cancer risk in rural Africans and African Americans. American Journal of Clinical Nutrition 98:111-120. DOI: 10.3945/ajcn.112.056689.

Quast C., Pruesse E., Yilmaz P., Gerken J., Schweer T., Yarza P., Peplies J., Glöckner FO. 2013. The SILVA ribosomal RNA gene database project: improved data processing and webbased tools. Nucleic acids research 41:D590-6. DOI: 10.1093/nar/gks1219.

Sha S., Xu B., Wang X., Zhang Y., Wang H., Kong X., Zhu H., Wu K. 2013. The biodiversity and composition of the dominant fecal microbiota in patients with inflammatory bowel disease. Diagnostic Microbiology and Infectious Disease 75:245-251. DOI: 10.1016/j.diagmicrobio.2012.11.022.

Sivaprakasam S., Gurav A., Paschall A V., Coe GL., Chaudhary K., Cai Y., Kolhe R., Martin P., Browning D., Huang L., Shi H., Sifuentes H., Vijay-Kumar M., Thompson SA., Munn DH., Mellor A., McGaha TL., Shiao P., Cutler CW., Liu K., Ganapathy V., Li H., Singh N. 2016. An essential role of Ffar2 (Gpr43) in dietary fibre-mediated promotion of healthy composition of gut microbiota and suppression of intestinal carcinogenesis. Oncogenesis 5:e238. DOI: 10.1038/oncsis.2016.38.

Sze MA., Schloss PD. 2016. Looking for a Signal in the Noise: Revisiting Obesity and the Microbiome. mBio 7:e01018-16. DOI: 10.1128/mBio.01018-16.

Team RC. 2014. R: A language and environment for statistical computing.

Turnbaugh PJ., Hamady M., Yatsunenko T., Cantarel BL., Ley RE., Sogin ML., Jones WJ., Roe BA., Jason P., Egholm M., Henrissat B., Heath AC., Knight R., Gordon JI. 2009. A core gut microbiome in obese and lean twins. 457:480-484. DOI: 10.1038/nature07540.A.

Turnbaugh PJ., Ley RE., Mahowald MA., Magrini V., Mardis ER., Gordon JI. 2006. An obesityassociated gut microbiome with increased capacity for energy harvest. Nature 444:1027131. DOI: $10.1038 /$ nature05414. 
448

449

450

451

452

453

454

455

456

457

458

459

460

461

462

463

464

465

466

467

468

469

470

471

472

473

474

475

476

477

478

479

480

481

482

483

484

485

486

Tyakht A V., Kostryukova ES., Popenko AS., Belenikin MS., Pavlenko A V., Larin AK., Karpova IY., Selezneva O V., Semashko TA., Ospanova EA., Babenko V V., Maev I V., Cheremushkin S V., Kucheryavyy YA., Shcherbakov PL., Grinevich VB., Efimov OI., Sas EI., Abdulkhakov RA., Abdulkhakov SR., Lyalyukova EA., Livzan MA., Vlassov V V., Sagdeev RZ., Tsukanov V V., Osipenko MF., Kozlova I V., Tkachev A V., Sergienko VI., Alexeev DG., Govorun VM., O’Hara AM., Shanahan F., Lagier J-C., Million M., Hugon P., Armougom F., Raoult D., Qin J., Wu GD., Yatsunenko T., Filippo C De., Claesson MJ., Nam Y-D., Jung M-J., Roh SW., Kim M-S., Bae J-W., Qin J., Clarke KR., Lozupone C., Knight R., Arumugam M., Suzuki R., Shimodaira H., Russell DA., Ross RP., Fitzgerald GF., Stantona C., Karlsson FH., Koren O., Leitch EC., Walker AW., Duncan SH., Holtrop G., Flint HJ., Ze X., Duncan SH., Louis P., Flint HJ., Belenguer A., Scheppach W., Pryde SE., Duncan SH., Hold GL., Stewart CS., Flint HJ., Varemo L., Nielsen J., Nookaew I., Mahowald MA., Martens EC., Flint HJ., Scott KP., Duncan SH., Louis P., Forano E., Xu J., Lee S., Sung J., Lee J., Ko G., Schloissnig S., Forslund K., Walker AW., Liefert W., Jahns L., Baturin A., Popkin BM., Murphy MM., Douglass JS., Birkett A., Brouns F., Kettlitz B., Arrigonix E., Yu Z., Morrison M., Iverson V., Langmead B., Trapnell C., Pop M., Salzberg SL., Langmead B., Salzberg S., Segata N., Edgar RC., Caporaso JG., Oksanen J., Henning C., Maechler M., Rousseeuw P., Struyf A., Hubert M., Hornik K., Goslee SC., Urban DL., Zhu W., Lomsadze A., Borodovsky M. 2013. Human gut microbiota community structures in urban and rural populations in Russia. Nature Communications 4:688-693. DOI: $10.1038 /$ ncomms3469.

Varlet V., Farsalinos K., Augsburger M., Thomas A., Etter JF. 2015. Toxicity assessment of refill liquids for electronic cigarettes. International Journal of Environmental Research and Public Health 12:4796-4815. DOI: 10.3390/ijerph120504796.

Wang H. 2012. Side-stream smoking reduces intestinal inflammation and increases expression of tight junction proteins. World Journal of Gastroenterology 18:2180. DOI: 10.3748/wjg.v18.i18.2180.

Wu J., Peters BA., Dominianni C., Zhang Y., Pei Z., Yang L., Ma Y., Purdue MP., Jacobs EJ., Gapstur SM., Li H., Alekseyenko A V., Hayes RB., Ahn J. 2016. Cigarette smoking and the oral microbiome in a large study of American adults. The ISME Journal 10:2435-2446. DOI: $10.1038 /$ ismej.2016.37.

$\mathrm{Xu}$ J., Gordon JI. 2003. Honor thy symbionts. Proceedings of the National Academy of Sciences of the United States of America 100:10452-9. DOI: 10.1073/pnas.1734063100.

You R., Lu W., Shan M., Berlin JM., Samuel EL., Marcano DC., Sun Z., Sikkema WK., Yuan X., Song L., Hendrix AY., Tour JM., Corry DB., Kheradmand F. 2015. Nanoparticulate carbon black in cigarette smoke induces DNA cleavage and Th17-mediated emphysema. eLife 4:e09623. DOI: 10.7554/eLife.09623.

Yu G., Phillips S., Gail MH., Goedert JJ., Humphrys MS., Ravel J., Ren Y., Caporaso NE. 2017. The effect of cigarette smoking on the oral and nasal microbiota. Microbiome 5:3. 


\section{Table $\mathbf{1}$ (on next page)}

Subject information for the human cohort per exposure group

Abbreviations: IQR, interquartile range; FTND, Fagerstrom test for nicotine dependence 
1 Table 1 - Subject information for the human cohort per exposure group

\begin{tabular}{llll}
\hline & Controls & $\begin{array}{l}\text { Electronic } \\
\text { Cigarette (EC) }\end{array}$ & $\begin{array}{l}\text { Tobacco Smoke } \\
(\mathrm{TS})\end{array}$ \\
\hline $\begin{array}{l}\text { Male sex } \\
\text { Age in years, median (IQR) }\end{array}$ & $90 \%$ & $90 \%$ & $100 \%$ \\
Diet & $31(28-36)$ & $29(24-37)$ & $35(30-45)$ \\
$\quad$ Meat eater & $90 \%$ & $90 \%$ & $100 \%$ \\
$\quad$ Vegetarian & $10 \%$ & 0 & 0 \\
$\quad$ Vegan & 0 & $10 \%$ & 0 \\
Body mass index, median (IQR) & $23.5(22.5-24.5)$ & $24.5(22.5-26.7)$ & $24(21.5-25.5)$ \\
Race & & & \\
$\quad$ White & $60 \%$ & $70 \%$ & $60 \%$ \\
$\quad$ Hispanic & $10 \%$ & $20 \%$ & $10 \%$ \\
$\quad$ Asian & $30 \%$ & $10 \%$ & 0 \\
$\quad$ Black & 0 & 0 & $30 \%$ \\
Electronic Cigarette & & & - \\
$\quad$ Nicotine concentration (mg), median (IQR) & - & $9(6-12)$ & - \\
$\quad$ Volume (mL) / day, median (IQR) & - & $8(3-19)$ & - \\
$\quad$ Years using, median (IQR) & - & $3(2-4)$ & \\
Tobacco smoke & & & $14(10-19)$ \\
$\quad$ Cigarettes / day, median (IQR) & 0 & $0.2(0.2-0.2)$ & $5(4-6)$ \\
FTND, median (IQR) & 0 & $3(3-4)$ & $19(14-24)$ \\
$\quad$ Carbon monoxide (ppm), median (IQR) & $1(1-2)$ & & \\
\hline
\end{tabular}

3 Abbreviations: IQR, interquartile range; FTND, Fagerstrom test for nicotine dependence 
Figure 1 (on next page)

Boxplots of bacterial alpha diversity

Analysis stratified per sample type. Controls (Con; orange); electronic cigarette (EC; blue); tobacco smoke (TS; green). Significance based on non-parametric Mann-Whitney test with FDR adjustment for multiple comparisons. Number of operational taxonomic units (OTUs) (A) and Shannon diversity (B) in feces. Number of OTUs (C) and Shannon diversity (D) in buccal swabs. Number of OTUs (E) and Shannon diversity (F) in saliva. 
Kruskal-Wallis $\mathrm{P}=0.375$ Observed OTUs
B Kruskal-Wallis $P=0.018$ Shannon

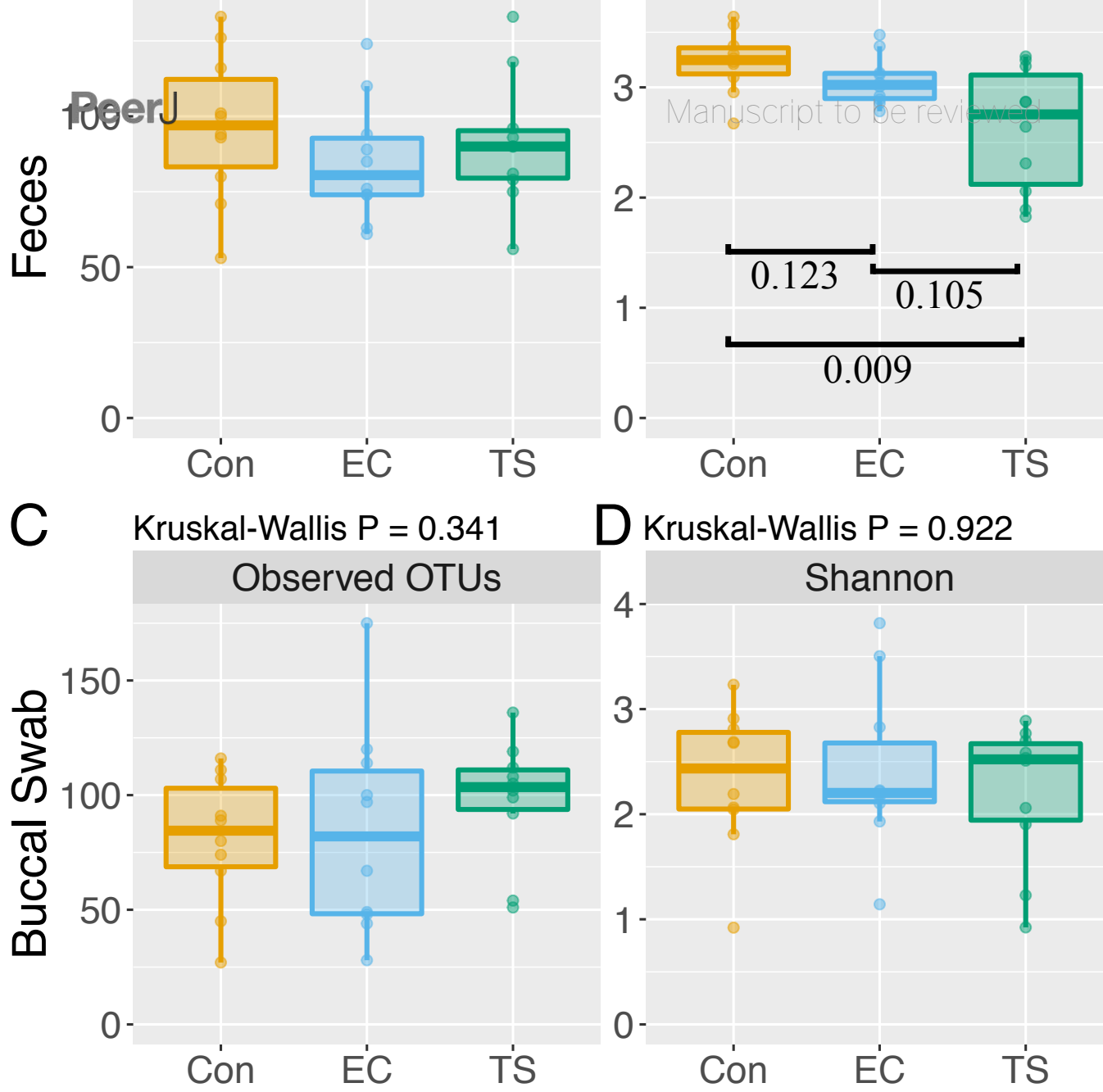

$\stackrel{\frac{\pi}{2}}{\pi}$

Kruskal-Wallis $\mathrm{P}=0.098$ Observed OTUs

150
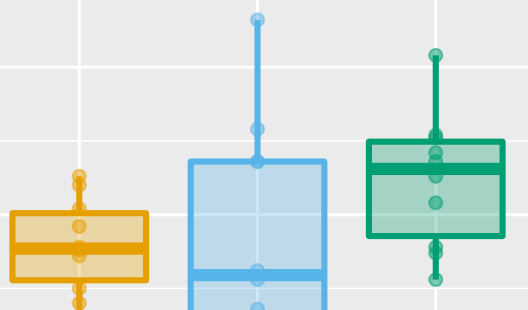

Peer) reviewing PDF | (2018:02:25374:2:0:NEW 7 Apr 2018)

50 -

F Kruskal-Wallis $\mathrm{P}=0.171$

Shannon

$3-$
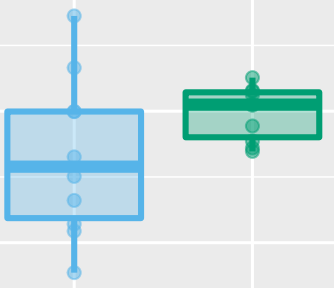

2.

0

0 -

Con

E'C 


\section{Figure 2 (on next page)}

Weighted UniFrac principal coordinate analysis (PCOA)

Analysis stratified per sample type. Controls (Con; orange); electronic cigarette (EC; blue); tobacco smoke (TS; green). Significance based on PERMANOVA. (A) Feces. (B) Buccal swab. (C) Saliva. 


\section{Figure $\mathbf{3}$ (on next page)}

Boxplot analysis of the bacterial genera in feces per exposure group

Genera ordered based on lowest P value. All genera with $>1 \%$ mean abundance included. Boxes represent interquartile ranges, with lines denoting median. Controls (Con; orange); electronic cigarette (EC; blue); tobacco smoke (TS; green). Kruskal-Wallis test with FDR adjustment for multiple comparisons showed 2 taxa significantly altered in feces, Prevotella $(P=0.006)$ and Bacteroides $(P=0.036)$. Mann-Whitney Pairwise comparisons for Prevotella showed significantly increased relative abundance in TS compared to Con $(P=0.008)$ and EC $(P=0.003)$, but no difference between $E C$ and Con $(P=0.99)$. Mann-Whitney Pairwise comparisons for Bacteroides showed significantly decreased relative abundance in TS compared to Con $(P=0.017)$ and $E C(P=0.003)$, but no difference between $E C$ and $C o n(P=$ $0.684)$. 
Genera in Feces Samplesewith at least $1 \%$ Mean Abundance

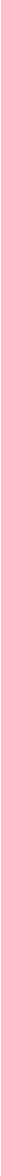

